九州大学学術情報リポジトリ

Kyushu University Institutional Repository

\title{
Significant Propagation Loss Reduction on Silicon High-Mesa Waveguides Using Thermal Oxidation Technique
}

Han, Yu

I-EggS (Interdisciplinary Graduate School of Engineering Sciences), Kyushu University

Li, Wenying

I-EggS (Interdisciplinary Graduate School of Engineering Sciences), Kyushu University

Jiang, Haisong

I-EggS (Interdisciplinary Graduate School of Engineering Sciences), Kyushu University

Hamamoto, Ki ichi

I-EggS (Interdisciplinary Graduate School of Engineering Sciences), Kyushu University

https://doi.org/10.15017/2552950

出版情報: Proceedings of International Exchange and Innovation Conference on Engineering \& Sciences (IEICES). 5, pp. 100-102, 2019-10-24. Interdisciplinary Graduate School of Engineering Sciences, Kyushu University バージョン：

権利関係 : 


\title{
Significant Propagation Loss Reduction on Silicon High-Mesa Waveguides Using Thermal Oxidation Technique
}

\author{
Yu Han*, Wenying Li, Haisong Jiang, and Kiichi Hamamoto \\ I-EggS (Interdisciplinary Graduate School of Engineering Sciences), Kyushu University \\ 6-1, Kagugakouen, Kasuga, Fukuoka 816-8580, Japan \\ *E-mail: han.yu.926@s.kyushu-u.ac.jp
}

\begin{abstract}
Breath sensing system based on cavity ring-down spectroscopy (CRDS) technique is attractive due to its real time sensing in addition to the capability of high sensitivity. Utilizing waveguide for CRDS may realize ppm-order components into a compact area. This work have exploited thermal oxidation technique to silicon high-mesa waveguides for sensing-application. Significant propagation loss reduction from 1.45 to $0.84 \mathrm{~dB} / \mathrm{cm}$ at a waveguide width of $500 \mathrm{~nm}$ has been achieved by the technique successfully.
\end{abstract}

Keywords: Loss reduction, High-mesa waveguide, Thermal oxidation, CRDS.

\section{INTRODUCTION}

Breath sensor is a noninvasive and convenient fashion for health-monitoring [1]. In order to detect ppm-order breath content in addition to the real time sensing, breath sensing system based on cavity ring-down spectroscopy (CRDS) technique has been researched as a candidate [2] Compared to the conventional bulk CRDS system [3], utilizing waveguide as the gas sensing cell may realize several meters sensing path which is needed for measuring ppm-order components in human breath within a compact area [4]. This brings the possibility of integrating CRDS system into a cell phone or other mobile equipment for powerful in-situ and real-time health-monitoring. One issue is the propagation loss of the waveguide as it may prevent ppm-order gas detection.

In a CRDS system, the length of a regular sensing cell is about 1 meter needed for measuring ppm-order breath content $[3,5]$. If the propagation loss of the waveguide exceeds $0.2 \mathrm{~dB} / \mathrm{cm}$, the total loss of the waveguides is higher than $20 \mathrm{~dB}$. This high loss causes the waveguide impossible to be used even if an optical amplifier is introduced in the CRDS system [5]. A 1 m-long waveguide with the propagation loss $\leq 0.2 \mathrm{~dB} / \mathrm{cm}$ is required to be applied as the sensing cell. Recently, a novel high-mesa waveguide structure has been proposed by our group for the compact and high-sensitive CRDS system [4, 6, 7]. Compared to the slot waveguide [8] and the conventional channel waveguide, it not only provides the evanescent field sufficient touching the breath gas, but also avoids the surface to be contaminated by particles in air. A high-mesa silicon-on-insulator (SOI) waveguide with $260-\mathrm{nm}$ thick silicon ( $\mathrm{Si}$ ) as the core has been fabricated $[6,7]$, but its propagation loss $(\alpha)$ was still too high to be as the sensing cell [9].

In order to decrease $\alpha$, this work designed and fabricated a $100 \mathrm{~nm}$ thick Si high-mesa waveguides in this work. After fabrication, This work applied dry thermal Si oxidation technique for further reduction. After thermal oxidation, the propagation loss was effectively reduced from 1.45 to $0.84 \mathrm{~dB} / \mathrm{cm}$ for width $=0.5 \mu \mathrm{m}$ and from 0.29 to $0.2 \mathrm{~dB} / \mathrm{cm}$ for width $=3 \mu \mathrm{m}$. The reduction of $\alpha$ was attributed to the decrease of the sidewall scattering loss and the absorption loss from the damaged $\mathrm{Si}$.

\section{EXPERIMENTS and RESULTS}

The designed $100 \mathrm{~nm}$ thick Si high-mesa waveguide is shown in Fig. 1 (a). The device layer of the SOI is 100 $\mathrm{nm}$ and the top $\mathrm{SiO} 2$ cladding is $2 \mu \mathrm{m}$. The bottom $\mathrm{SiO} 2$ cladding is etched with a thickness of $1 \mu \mathrm{m}$. The width of the waveguide is variable to optimize $\alpha$.

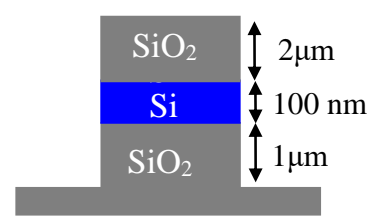

(a)

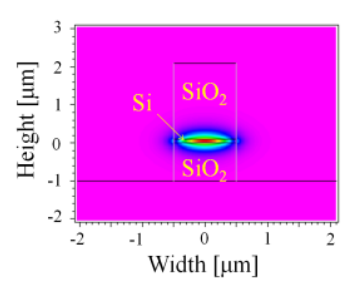

(b)
Fig. 1 Designed 100 nm-thick Si high-mesa waveguide. (a) Cross-section and (b) TE mode light profile when width $=1 \mu \mathrm{m}$

The propagation loss $\alpha$ of a waveguide is generally attributed to three different mechanisms: radiation loss, absorption loss and scattering loss. The simulated TE mode in Fig. 1(b) indicates that the optical field is wellconfined in the waveguide. In addition, the materials, $\mathrm{Si}$ and $\mathrm{SiO}_{2}$, are highly transparent around $1550 \mathrm{~nm}$. As a result, the main reasons of $\alpha$ in our case are the scattering loss $\alpha_{\text {scattering }}$ origining from the rough sidewall and the

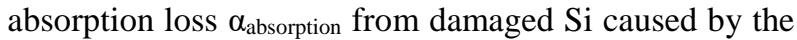
ICP etching. Oxidation of $\mathrm{Si}$ has been shown to be effective at reducing the sidewall scattering and recovering the damaged $\mathrm{Si}$ [4]. After oxidation, a thin $\mathrm{Si}$ layer near the sidewall is oxidized into $\mathrm{SiO}_{2}$, so that the effective refractive index $\left(\mathrm{n}_{\mathrm{eff}}\right)$ of waveguide is reduced and the damaged $\mathrm{Si}$ is recovered. According to the PayneLacey model [5], a lower $n_{\text {eff }}$ indicates a lower $\alpha_{\text {scattering. }}$. In addition, the $\alpha_{\text {absorption }}$ from damaged $\mathrm{Si}$ is also reduced due to the transformation to $\mathrm{SiO}_{2}$. Based on the design and analysis above, high-mesa waveguides were fabricated on a SOI wafer. A $2 \mu$ m-thick $\mathrm{SiO} 2$ top cladding was deposited on the SOI wafer via chemical vapor deposition. The wafer was coated with electron beam (EB) resist SU-8 and patterned by EB lithography. The exposed wafer was etched in an inductively coupled plasma (ICP) etching machine by using CHF3 gas. 
Finally, This work applied dry thermal oxidation at $1000{ }^{\circ} \mathrm{C}$ from 1 to 4 hours (hrs) under the gas condition as $\mathrm{O} 2: \mathrm{N} 2=1: 4$ (mole ratio). The propagation loss $\alpha$ was evaluated by using Fabry-Perot interferometric method [14]. Light from a distributed feedback laser source was coupled into the waveguide in TE mode through a polarization-maintaining lensed fiber. A polarizer was used to align the input light polarization between the laser and the fiber. Output optical power of the waveguide is collected using a photo-detector and the detected data were recorded automatically by a computer.

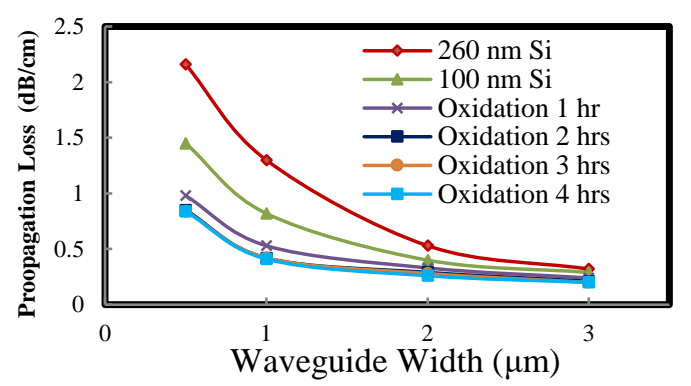

(a)

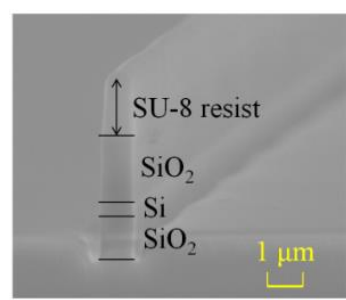

(b)

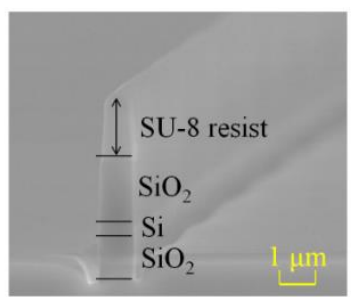

(c)
Fig. 2 Optical properties of the high-mesa waveuides

(a) Measured propagation loss before and after oxidation (260 nm data for comparison) and Captured SEM images (b) before oxidation and (c) after $4 \mathrm{hrs}$ oxidation.

The estimated $\alpha$ as a function of the waveguide width is shown in Fig. 2 (a). The loss of $100 \mathrm{~nm} \mathrm{Si} \mathrm{waveguides} \mathrm{at}$ the wavelength of $1550 \mathrm{~nm}$ even without oxidation are lower than those of $260 \mathrm{~nm}-\mathrm{Si}$ waveguides. This is because that the effective refractive index (neff) is lower when the Si core is thinner and thus the ascattering is lower according to the Payne-Lacey model. After sufficient oxidation ( $\geqslant 3 \mathrm{hrs}$ ), $\alpha$ is effectively reduced from 1.45 to $0.84 \mathrm{~dB} / \mathrm{cm}$ for width $=0.5 \mu \mathrm{m}$ and from 0.29 to $0.2 \mathrm{~dB} / \mathrm{cm}$ for width $=3 \mu \mathrm{m}$, which follows our above analysis of the oxidation of $\mathrm{Si}$. Longer time oxidation (4 hrs) does not induce obvious further reduction of $\alpha$, which is attributed to the formation of $\mathrm{SiO} 2$ preventing oxygen from diffusing through the grown oxide film into the Si [15]. Figure 2(b) and (c) show the SEM images of the $1 \mathrm{um}$ wide waveguide before oxidation and after $4 \mathrm{hrs}$ oxidation, respectively. The waveguide structure seems to be secure even after long oxidation process as shown in Fig. 2(b) and (c).

\section{DISCUSSIONS}

From Fig. 2(a), the curve slope of the measured $\alpha$ becomes lower and lower with the increasing waveguide width. When the width reaches around $3 \mu \mathrm{m}$, the curve seems to be almost flat, which indicates that $\alpha$ goes constant when the width $>3 \mu \mathrm{m}$. Therefore, $\alpha$ at the width of 3 um is considered to be totally caused by the damaged $\mathrm{Si}$ absorption $\alpha$ absorption. By using thermal oxidation, aabsorption has been reduced down from 0.29 to 0.2 $\mathrm{dB} / \mathrm{cm}$. Subsequently, ascattering at each waveguide width is readily obtained just by using $\alpha$ scattering $=\alpha-$ aabsorption. According to the Payne-Lacey model [13], ascattering is given as follows

$$
\alpha_{\text {scattering }} \propto\left(n_{\text {eff }}-n_{0}\right)^{2} \sigma^{2} \Gamma_{\text {air }}
$$

where $\mathrm{n} 0$ is the refractive index of the cladding, $\sigma$ the sidewall roughness and $\Gamma$ air the portion of the guided light out of the waveguide. This work fitted the ascattering according to Eq. 1 by continuously changing $\sigma$ until the fitted curve overlaps with the measured result. When the $\sigma$ is $11.5 \mathrm{~nm}$, for the un-oxidated waveguides, This work find that the fitted and measured curves overlap each other well. After sufficient oxidation $(\geqslant 3$ hrs), the fitted and measured curves overlap each other well when the $\sigma$ is $9.4 \mathrm{~nm}$, which means that the oxidation improves the $\sigma$ as high as $2.1 \mathrm{~nm}$. This $2.1 \mathrm{~nm}$ can not be observed in Fig. 2(b) and (c) obviously because of the limilted resolution of the SEM.

Based on the $3 \mu \mathrm{m}$ wide waveguide, This work design a photonic integrated circuit for the CRDS system as schematically shown Fig. 3. On the chip, it integrates a tunable laser (TL), a semiconductor optical amplifier (SOA), an optical coupler (CP) with a splitting ratio 9:1, a $1 \mathrm{~m}$ long waveguide gas sensing (WGS) cell and a photo-detector (PD) [4]. In this work, This work take $\mathrm{CH} 4$ for the targeted gas as an example and use the $3 \mu \mathrm{m}$ wide waveguide with the measured $\alpha=0.2 \mathrm{~dB} / \mathrm{cm}$ and the calculated $\Gamma$ air $=2.6 \%$. In the CRDS system, the ringdown times are 200, which means the effective sensing path is $200 \mathrm{~m}$ [4]. Consequently, the sensitivity of the integrated CRDS circuit is determined by the $\alpha$ and $\Gamma$ air of the WGS and the CH4 absorption cross section. The detailed calculation method has been demonstrated in our previous work [4]. Based on this method, the calculated sensitivity of the CRDS is ranging from 104 to $10 \mathrm{ppm}$ depending on the gain of the SOA [5]. Since the CH4 concentration in exhaled breath of 2-10 ppm indicates a buerger disease [4], our waveguide has a promising potential to be applied in an integrated CRDS system.

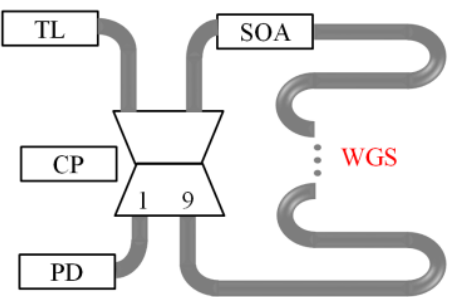

Fig. 3 Schematic of designed photonic integrated circuit for the CRDS systerm

\section{CONCLUSIONS}

Authors have designed and fabricated $100 \mathrm{~nm}$-thick Si core high-mesa waveguides for breath sensors. By using dry thermal oxidation, $\alpha_{\text {scattering }}$ and $\alpha_{\text {absorption }}$ are reduced effectively and the final achieved $\alpha$ satisfies the requests of the low loss of a compact CRDS system. 


\section{ACKNOWLEDGMENT}

This work is supported in finance by SECOM Science and Technology Foundation.

\section{REFERENCES}

[1] T. H. Risby and S. F. Solga, Current status of clinical breath analysis, Appl. Phys. B, vol. 85, 2006, pp. 421426.

[2] G. Berden, R. Peeters, and G. Meijer, Cavity ringdown spectroscopy: Experimental schemes and applications, Int. Rev. Phys. Chem., vol. 19, 2000, pp. 565-607.

[3] J. Manne, O. Sukhorukov, W. Jager, and J. Tulip, Pulsed quantum cascade laser-based cavity ring-down spectroscopy for ammonia detection in breath,Appl. Opt., vol. 45, 2006, pp. 9230-9237.

[4] J. Chen, H. Hokazono, D. Nakashima, M. Tsujino, Y. Hashizume, M. Itoh and K. Hamamoto, Low loss silica high-mesa waveguide for infrared sensing, Jpn. J. Appl. Phys., vol. 53, 2014, pp. 022502.

[5] W. Li, Y. Han, Z. Chen, H. Jiang, and K. Hamamoto, Amplifier Assisted CRDS (Cavity Ring-down Spectroscopy) toward Compact Breath Sensing, IEICE vol. 118, no. 399, 2019, pp. 251-254.

[6] A. Intekhab, SOI-based $\mathrm{Si} / \mathrm{SiO} 2$ High-mesa Waveguide for Optical Absorption Sensing, Thesis, Kyushu Univ., 2013.

[7] D. Nakashima and K. Hamamoto, Proposal of novel strip high-mesa waveguide for infrared absorption sensing, Appl. Phys. Express, vol. 5, 2012, pp. 062202.

[8] F. D. Olio and V. M. Passaro, Optical sensing by optimized silicon slot waveguides, Opt. Express, vol. 15, 2007, pp. 4977-4993.

[9] Y. Han, W. Li, H. Jiang and K. Hamamoto, Thin core (100nm) silicon high-mesa waveguide for high quality breath sensors, IEICE Tech. Rep., vol. 118, 2018, pp. 8792.

[10] K. K. Lee, D. R. Lim, and L. C. Kimerling, Fabrication of ultralow-loss $\mathrm{Si} / \mathrm{SiO} 2$ waveguides by roughness reduction, Opt. Lett., vol. 26, 2001, pp. 1888 1890.

[11] A. Yahata, S. Urano, T. Inoue, and T. Shinohe, Smoothing of Si trench sidewall surface by chemical dry etching and sacrificial oxidation, Jpn. J. Appl. Phys., vol. 37, p. 7, 1998.

[12] F. P. Payne and J. P. R. Lacey, A theoretical analysis of scattering loss from planar optical waveguides, Opt. and Quantum Electron., vol. 26, 1994, pp. 977-986.

[13] S. Taebi, M. Khorasaninejad, and S. S. Saini, Modified Fabry-Perot interferometric method for waveguide loss measurement, Appl. Opt., vol. 47, 2008, pp. 6625-6630.

[14] M. Liu, P. Jin, Z. Xu, D. A. H. Hanaor, Y. Gan, and C. Chen, Two-dimensional modeling of the self-limiting oxidation in silicon and tungsten nanowires, Theor. Appl. Mech. Lett., vol. 6, 2016, pp. 195-199. 